\title{
Study on black carbon and its characterisation at an urban location, Hyderabad during 2010 to 2012
}

\author{
Subin Jose, Biswadip Gharai \\ Atmospheric \& Climate Sciences Group, ECSA, NRSC, Dept. of Space-Govt. of India, Balanagar, Hyderabad, India \\ Email address: \\ subinjose22@gmail.com (S. Jose), g.biswadip@gmail.com (B. Gharai)
}

To cite this article:

Subin Jose, Biswadip Gharai. Study on Black Carbon and Its Characterisation at an Urban Location, Hyderabad during 2010 to 2012. International Journal of Environmental Monitoring and Analysis. Vol. 2, No. 2, 2014, pp. 100-105. doi: 10.11648/j.ijema.20140202.16

\begin{abstract}
A seven channel Aethalometer (AE31) was used to measure the black carbon (BC) mass concentrations at the premises of National Remote Sensing Centre (NRSC), Hyderabad during the period 2010-2012 to characterize BC temporal concentration and source identification. Diurnal variation of $\mathrm{BC}$ shows varied amplitude of $\mathrm{BC}$ mass concentration with peak during mornings and nights with minimum during afternoons of all the study periods (2010-2012). Highest absorption coefficient at $520 \mathrm{~nm}\left(b_{a b s}=38.79 \mathrm{Mm}^{-1}\right)$ was observed during post monsoon season of 2011 and lowest value observed ( $b_{\text {abs }}$ $=22.06 \mathrm{Mm}^{-1}$ ) during winter season of 2010. Absorption Angstrom Exponents (AAE) were analysed in the lower (370 $\mathrm{nm}-520 \mathrm{~nm}$ ) and higher wavelength $(590 \mathrm{~nm}-950 \mathrm{~nm}$ ) region to explain the BC origin. A few number of days with high contrasting AAE in lower and higher wavelengths, responsible for the bio fuel generated $\mathrm{BC}$ were found during the study period. Study revealed that majority of the study period, AAE values are around 1, attributed to mainly vehicular emission. Highest AAE of $1.57(370 \mathrm{~nm}-950 \mathrm{~nm})$ was observed on 4 January, 2012. Three representative days of pre-monsoon, post-monsoon and winter were considered for analyzing daily variations of AAE in conjunction with back trajectories from NOAA HYSPLIT model to confirm the source of $\mathrm{BC}$ as biomass burning origin.
\end{abstract}

Keywords: BC, Absorption Coefficient, AAE

\section{Introduction}

$\mathrm{BC}$ is identified as the light absorbing fraction of the carbonaceous aerosols or elemental carbon fraction, which is emitted through incomplete combustion of carbon containing fuels. These fuels are mainly coming from fossil, gasoline and diesel fuels, bio-fuels and biomass burning as discussed by Bond et al., 2004 [1] and therefore much atmospheric BC is of anthropogenic origin. Since BC absorbs solar radiation most effectively than it reflects, thus warms the atmosphere through its interaction with sunlight $[2,3]$. Black carbon influences the microphysical properties of clouds and changes its albedo through diverse and complex process; which in turn reflects in radiative changes in the atmosphere, this is termed as the climate indirect effect of Black Carbon. This indirect effect is one of the largest sources of uncertainty in quantifying black carbon's role in climate system $[4,5]$. Because the short life span of $\mathrm{BC}$ in atmosphere climatic effect at regional scale is more prominent than at global scale [6,7].The sources that emit $\mathrm{BC}$ also emit other aerosol species and gases, namely sulphur containing particles, Organic Carbon (OC) ,nitrate aerosols and long lived GHG's. These co emitted aerosol particles absorb little light, so they often warm the climate. $\mathrm{BC}$ is considered to be the second largest contributor to global warming after $\mathrm{CO}_{2}[8,9]$. Recent studies found that total estimated climate forcing of black carbon is about $+1.1 \mathrm{w} / \mathrm{m}^{2}$ approximately two thirds of the effect of the largest man made contributor to global warming, carbon dioxide [5].

In India, the main source of $\mathrm{BC}$ is from incomplete combustion from diesel engines, bio fuels and biomass burning [6]. Over the past one decade there has been a significant increase in these sources, as result of growing urbanisation and increased deforestation. For example in Hyderabad which is one of the metropolitan cities in the country total number of vehicles has increased sharply over past decade (www. apsrtc.com). The quantity and composition of biomass combustion particles depend upon several factors including composition and size of the fuel, terrain and weather. In addition, the duration of flaming versus smouldering must also be considered as discussed by Lobert and Warnatz, (1993) [10]. Another main source of carbonaceous aerosols is burning of agriculture residue, 
which not only modulates the regional climate [11], but also affects the other part through long range transport [12]. Over India, $\mathrm{BC}$ emissions $\left(\mathrm{Gg} \mathrm{yr}^{-1}\right)$ from fossil fuel, open burning, and biofuel combustion contribute around $25 \%, 33 \%$, and $42 \%$, respectively as discussed by Venkatraman et al, (2005), [13]. BC concentrations reported over Indian cities were found to be quite high when compared to cities in other parts of the world as discussed by Ganguly et al, (2006) [14]; Latha and Badarinath, (2005) [15] and Babu and Moorthy, (2002) [16].

Fresh Soot is normally hydrophobic and therefore acts as poor $\mathrm{CCN}$ and its absorption coefficients also shows poor spectral dependence in the solar spectrum [17, 18]. Bond and Bergstrom, [19] have calculated the mass absorption efficiency for fresh soot aggregates at $550 \mathrm{~nm}$ to be $7.15 \pm 1.2 \mathrm{~m}^{2} / \mathrm{g}$. But soot can become increasingly hydrophilic by condensation of atmospheric $\mathrm{O}_{3}, \mathrm{SO}_{2}, \mathrm{NO}_{x}$, $\mathrm{HNO}_{3}$ and secondary organic aerosols on the particle surface, which is referred as particle ageing [20, 21]. Fuller et al, (1999) [22] have shown that a complete encapsulation of a soot core with a non absorbing organic or inorganic condensates might enhance the absorption by $30-50 \%$ and hence have a stronger spectral dependence of absorption coefficient.

In the present study we analysed seasonal and diurnal variations of $\mathrm{BC}$ using three years continuous measurements on $\mathrm{BC}$ and attempt to identify probable contributors of $\mathrm{BC}$ in an urban area, Hyderabad. We have used seven channel Aethalometer AE31 (Magee scientific) data to calculate absorption coefficients and AAE at different wavelengths ranges to study the presence of biomass aerosols or dust aerosol in addition to local emissions. Long-range transport of $\mathrm{BC}$ component from biomass burning is analyzed using back trajectories from the NOAA HYSPLIT model in conjunction with spatial distribution of Terra/Aqua MODIS derived fire locations.

\section{Experimental Site}

Present study was conducted at the campus of NRSC, Hyderabad $\left(17.47^{0} \mathrm{~N}, 78.43^{\circ} \mathrm{E}\right)$, which is located in a purely urban location. Hyderabad is the capital of the $5^{\text {th }}$ largest populated state, Andhra Pradesh ( 84.7 million) in India. Hyderabad alone has a population of 4.01 million (census 2011). The city is influenced by vehicular emission, long range transport of $\mathrm{BC}$ from biomass burning and industrial emissions. The four dominant seasons prevailed here are winter (December-February), pre-monsoon (March-May), monsoon (June-September) and post-monsoon (October-November). Fifty years (1951-2000) climatology data of Hyderabad as available at the India Meteorological Department site ( $w w w$. imd. gov. in) shows an average maximum temperature of $39^{\circ} \mathrm{C}$ occurs during May with a peak of $41.4^{\circ} \mathrm{C}$ and an average minimum of $14.4{ }^{\circ} \mathrm{C}$ during December with the lowest of $10.1{ }^{\circ} \mathrm{C}$. The average annual rainfall of Hyderabad is $\sim 830 \mathrm{~mm}$.

\section{Material and Methods}

Absorbing black carbon measurements were carried out using seven channels Aethalometer (model AE31, Magee Scientific, USA) at NRSC. The Aethalometer data was used to determine the absorption coefficient $\left(b_{\mathrm{abs}}\right)$ and Absorption Angstrom Exponent (AAE).

It uses quartz fiber filter tape through which air is passed for a fixed amount of time (5 minutes) with a selected constant flow rate ( $\sim 3$ LPM). Due to deposition of aerosols on fiber tape, light is attenuated through the tape, which is measured by Aethalometer at seven wavelengths $(370 \mathrm{~nm}$, $470 \mathrm{~nm}, 520 \mathrm{~nm}, 590 \mathrm{~nm}, 660 \mathrm{~nm}, 880 \mathrm{~nm}$ and $950 \mathrm{~nm})$. Attenuation of light through filter paper at $880 \mathrm{~nm}$ channel is considered standard for calculating $\mathrm{BC}$ concentration as there is no other major aerosol species which exhibits absorption at this wavelength [23]. The attenuation of light is converted to the recorded $\mathrm{BC}$ mass concentration using wavelength dependent calibration factors as recommended by the manufacturer (Aethalometer Manual, Magee Scientific). In a nearly unloaded condition, fiber filter causes multiple scattering, which in turn enhanced the light absorption. As the filter load is increased, optical path in the Aethalometer filter decreases, which underestimates the measured signals. This effect is termed as "shadowing effect", which causes Aethalometer attenuation measurement significantly different from the real. Hence to calculate true absorption coefficient, two corrections were made suggested by Weingartner et al., (2003) [24]; (1) multiple scattering caused by unloaded filter and (2) attenuation corrections required due to gradual accumulation of particles on the filter and thereby change of fraction of scattered light (shadowing effect). The absorption coefficient of the soot particles on fiber filter paper is defined as

$$
b_{A T N}=\frac{A}{Q} \frac{\Delta A T N}{\Delta t}
$$

Where $\mathrm{A}$ is the filter spot area $\left(1.67 \mathrm{~cm}^{2}\right), \mathrm{Q}$ the volumetric flow rate and $\triangle \mathrm{ATN}$ is the change in attenuation during the interval $\Delta \mathrm{t}$.

Since $b_{\text {ATN }}$ may differ significantly from the true aerosol absorption coefficient $b_{a b s}$ of airborne particles, the calibration factor $\mathrm{C}$ and $\mathrm{R}(\mathrm{ATN})$ are introduced as suggested by Weingartner et al., 2003 [24].

$$
b_{a b s}=b_{A T N} \frac{1}{C \cdot R(A T N)}
$$

where $\mathrm{C}$ and $\mathrm{R}$ describe the two effects which change the optical properties of particles embedded in the filter paper with respect to the properties of the same particles in the airborne state. The first effect $(\mathrm{C})$ is caused by multiple scattering of the light beam at the filter fibers in the unloaded filter with magnitude greater than unity. The constant $\mathrm{C}$ in equation (3) depends on filter paper and apparatus. We have used a $C$ value of 2.14 following Weingartner et al., (2003) [24]. R (ATN) in equation (3) is an empirical function of ATN as given below. 


$$
R(A T N)=\left(\frac{1}{f}-1\right) \frac{\ln (A T N)-\ln (10 \%)}{\ln (50 \%)-\ln (10 \%)}+1
$$

An empirical relation $b_{A T N}=b_{10 \%} R(A T N)$ was used to quantify shadowing effect as suggested by Weingartner et al.,2003[24]. Here $b_{10 \%}$ is the value of $b_{\text {ATN }}$ interpolated to $\mathrm{ATN}=10 \%$ and $\mathrm{f}$ is a measure of the slope of the plot between $b_{\text {ATN }}$ and attenuation (ATN) in percentage. " $f$ " values calculated for seven channels of Aethalometer during the noon time, when the sampled aerosol concentration was sufficiently constant.

The spectrally dependent aerosol absorption coefficients is given by a power law relationship $b_{a b s}(\lambda)=C \lambda^{-A A E}$, where $b_{a b s}(\lambda)$ is the aerosol absorption coefficient at wavelength $\lambda$, $\mathrm{C}$ a constant and AAE is the Absorption Angstrom Exponent as discussed by Kirchstetter et al, (2004) [18]. We calculated AAE by the negative slope of absorption vs. wavelength in a log-log plot. Since the biomass aerosol having higher absorption in the UV and visible region compared to fossil fuel aerosol, to identifying them separately we calculate AAE in the two wavelengths range $370 \mathrm{~nm}-520 \mathrm{~nm}$ and $590 \mathrm{~nm}$ $-950 \mathrm{~nm}$. The maximum uncertainty for BC can reach $20 \%$ (ranging from $\sim 40 \mathrm{ng} \mathrm{m}^{-3}$ to $60 \mathrm{ng} \mathrm{m}^{-3}$ ), with higher percentage error for low mass concentrations as discussed by Moorthy et al, (2007) [25]. Generally during summer, biomass burning (forest fire) is predominant compared to other season and agricultural residue burnings are predominant during post-monsoon/winter season. The roles of transport of $\mathrm{BC}$ component from biomass burning over Hyderabad are analyzed using back trajectories from NOAA HYSPLIT model.

Terra/Aqua MODIS active fire location data of 2010, 2011 and 2012 over Indian region obtained from FIRMS web site (http://firefly.geog.umd.edu/firms) were analysed in the current study. MODIS active fire detection is based on contextual algorithm developed by Giglio et al, (2003)[26], which exploits the strong emission of fires at $4 \mu \mathrm{m}$ and 11 $\mu \mathrm{m}$ spectral channels. Visible spectral channel along with thermal channels are used to eliminate cloud and water pixels. The brightness temperature at $4 \mu \mathrm{m}$ and $11 \mu \mathrm{m}$ are used for the absolute thresholding and background characterization before passing it through a series of contextual test to detect active fire. Details of MODIS active fire detection is given by Giglio et al, (2003)[26]. In the present study we have used the MODIS Terra/Aqua derived active fire locations in conjunction with back trajectories from NOAA HYSPLIT model to identify probable source of $\mathrm{BC}$ contributor (biomass burning).

\section{Results and Discussion}

The daily average and its hourly $\mathrm{BC}$ variations during the year 2010-12 are shown in Figure 1.

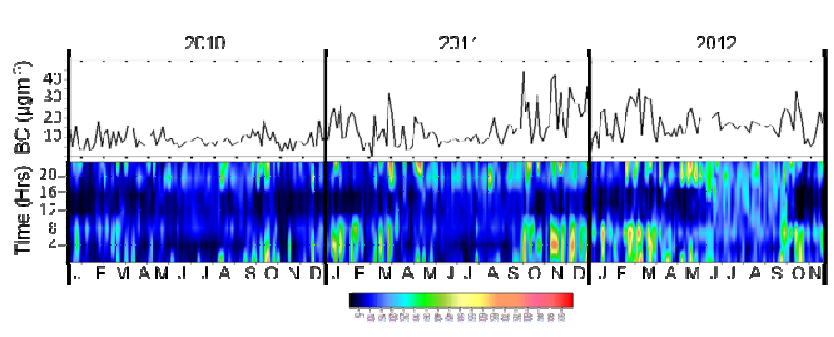

Figure 1. Daily (top panel) and hourly (bottom panel) average BC variations during the study period 2010-12.

In the figure, top panel shows the daily average variations and the bottom panel shows its diurnal variations. A large variation of $\mathrm{BC}$ mass concentrations is seen in the figure. Diurnal variation using individual hourly $\mathrm{BC}$ data of each day during 2010-12 (bottom panel of Figure 1), shows varied amplitude of mass concentration but the diurnal trend with peak during morning and night while afternoon minimum is maintained for all the years. It is clear from the figure that there is a gradual build up of $\mathrm{BC}$ mass concentration in the morning hours between 7:00 hrs and 9:00 hrs around an hour after the local sunrise. A nocturnal peak during 21:00 hrs to 02:00 hrs and afternoon minimum (11:00 hrs - 17:00 hrs) observed during the study period. The morning peak in $\mathrm{BC}$ is due to the well known fumigation effect in the boundary layer, which brings aerosols from the nocturnal residual layer shortly after the sunrise and also due to build up of local anthropogenic activities in the urban area [27]. Low values of BC during afternoon hours have been attributed to the dispersion of aerosols, due to increase in boundary layer height in addition to the low traffic density compared to morning and evening peak traffic movements. During rainy season, aerosol present in air got precipitate to ground resulting in lower value of $\mathrm{BC}$ mass concentration. It has been observed from the Figure 1 that $\mathrm{BC}$ values are relatively higher during monsoon period of 2012 than that observed during 2010 and 2011, which could be due to less rain fall occurred during 2012 compared to other two years (www.imd.gov.in).

The seasonal variations of absorption coefficients at 520nm during 2010-2012 are shown in Figure 2.

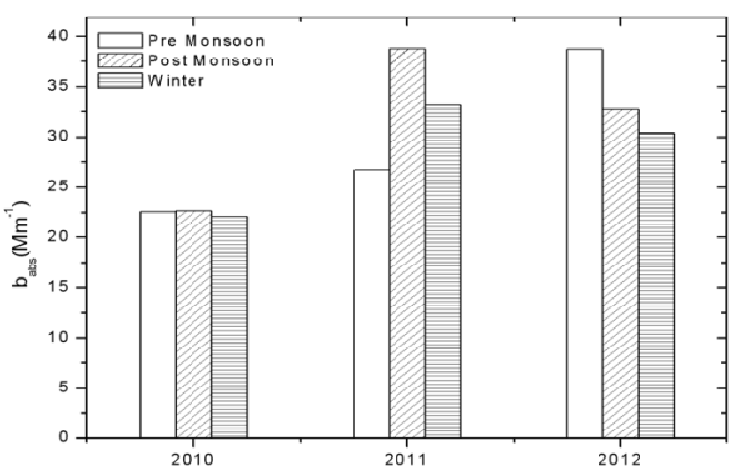

Figure 2. Seasonal variations of absorption coefficients at $520 \mathrm{~nm}$ during 2010-2012. 
Highest absorption coefficient (babs $=38.79 \mathrm{Mm}^{-1}$ ) observed during post monsoon season of 2011 and lowest value observed (babs $=22.06 \mathrm{Mm}^{-1}$ ) during winter season of 2010. This value is similar to those observed in other urban sites [28, 29]. In India, major forest fires (biomass burning) incident occurs during pre-monsoon season and agriculture residue burning during post-monsoon harvesting season. During winter, fire incident frequency is less than the other seasons. In a highly growing Indian city like Hyderabad, traffic densities have been increasing over a period. BC mass concentrations over Hyderabad are mainly due to vehicular emissions, although during pre-monsoon and post-monsoon season, there could be effect of biomass burning due to long range transport of $\mathrm{BC}$ component coming from forest fire and agriculture residue burning. To investigate the probable effect of biomass burning, in addition to background $\mathrm{BC}$ (due to vehicular origin), AAE were analysed in the lower $(370 \mathrm{~nm}-520 \mathrm{~nm})$ and higher wavelength $(590 \mathrm{~nm}-950 \mathrm{~nm})$ regions. Several studies have found that aerosols originating from fossil fuel combustion show weaker dependence on spectral light absorption, with the absorption Angstrom exponent (AAE) value close to 1 as discussed by Bergstrom et al., 2007[30]; Kirchstetter et al, (2004) [18] and an AAE values between 1 and 2 are indicating of mixture of $\mathrm{BC}$ origin from fossil and biomass fuel. The contrast between the events with biomass smoke and those with diesel soot smoke is most evident in the short wavelength spectrum. The high value of AAE $(>1)$ and its contrast in the shorter wavelengths $(370 \mathrm{~nm}-520 \mathrm{~nm})$ compared to higher wavelengths $(590 \mathrm{~nm}-950 \mathrm{~nm})$ have been investigated to identify the days which are affected by the biomass fuels. AAE during pre-monsoon, post-monsoon and winter season of 2010, 2011 and 2012 are respectively shown in Figure 3 a, $\mathrm{b}$ and $\mathrm{c}$. It is seen from the figure that most of the days AAE values are around 1, attributed to mainly vehicular emission except few days when AAE are high significantly. During 19 May,2010 representing pre-monsoon period showed a high contrast of AAE in the lower and higher wavelength with day average value of 1.20 in the lower wavelength $(370 \mathrm{~nm}$ $520 \mathrm{~nm})$ compared to 1.08 in higher wavelength (590 $\mathrm{nm}-950 \mathrm{~nm}$ ), could be identified as a day influenced by biomass burning. In our study area daily mean AAE for biomass fuel is less than that reported by Praveen et.al, 2012[31]; Bergstrom et al, (2007) [30]; Kirchstetter et al, (2004) [18]. Hourly variations of AAE (370 nm -950 nm) on 19 May, 2010, showed a peak of 1.32 during midnight, which could be associated with night fire. To confirm the biomass burning contribution, spatial distribution of fire locations obtained from Terra/Aqua MODIS over Indian region (600-1000 E and 00-400 N) were superimposed with backward trajectories ending at Hyderabad observations on 19 May,2010 as shown in Figure 4a. The NOAA HYSPLIT model run and meteorological fields from NCEP reanalysis data were used to study the transport of air mass over 7 days preceding to 19 May at two levels in the atmosphere at 1000 $\mathrm{m}$ (green colour) and $2000 \mathrm{~m}$ (blue colour) above ground level (AGL) ( Figure 4a). In the figure continuous line represent the mean air mass trajectory and dotted line represents the spread (0:0 hrs to 23:00 hrs UTC) of air mass trajectories. It is evident from the figure that air mass is coming over a number of fire locations, which confirmed the additional $\mathrm{BC}$ component from biomass burning added to background $\mathrm{BC}$ from vehicular emission.

In the similar way post-monsoon and winter representative dates of 29 October, 2010 and 14 January, 2012 were considered for further investigation. The 7 day backward trajectory and the fire locations were superimposed and are shown respectively in Figure $4 \mathrm{~b}$ and $4 \mathrm{c}$. Study suggest that on 29 October,2010 (post-monsoon), which coincide with post harvested agriculture residue burning period in north India was responsible for added $\mathrm{BC}$ concentration over Hyderabad by means of long range transport of $\mathrm{BC}$ component generated from biomass burning as evident in Figure $4 \mathrm{~b}$. The diurnal variations of AAE $(370 \mathrm{~nm}-950 \mathrm{~nm})$ reached to its peak of 1.33 on 29 October, 2010 and 1.57 on 14 January, 2012. Fires on 14 January,2012 representing winter season are mainly due to agriculture residue burning and thus produced $\mathrm{BC}$ component transporting to Hyderabad causing a contrast response of AAE (1.45 and 1.2) in the lower (370nm-520nm) and higher wavelength region $(590 \mathrm{~nm}-950 \mathrm{~nm})$. Since the study site is very close to heart of Hyderabad city, domestic fuels is quite non-existent as people use natural gas for cooking. Study revealed that the frequency of long range transport of $\mathrm{BC}$ component due to biomass burning are very less and the auto mobile exhaust is the main source of $\mathrm{BC}$ prevailed in the study site.

\section{Conclusion}

In the present study, we investigated the probable source of BC mass concentration over Hyderabad using 7 channels Aethalometer data during 2010-2012 periods.

The results of the study suggest that

- Diurnal variation of BC shows varied amplitude of mass concentration with peak during mornings and nights with a minimum in the afternoon for all study periods (2010-2012).

- $\quad$ Highest absorption coefficient (babs $=38.79 \mathrm{Mm}-1$ ) was observed during 2011 post monsoon and lowest value babs $=22.06 \mathrm{Mm}-1$ was observed during 2010 winter.

- $\quad$ Only a few number of days with high contrasting AAE in lower and higher wavelength region, responsible for the bio fuel generated $\mathrm{BC}$ were found during the study period.

- $\quad$ Highest AAE of 1.57 (370 nm-950 nm) was observed on 14 January, 2012.

- Auto mobile exhaust is the major contributor BC in the study site.

- In future, we will be experimenting using Aethalometer to analyse the response of AAE for different pure BC sources viz. bio fuel/Auto mobile exhaust in a controlled environment and thereby knowing the exact limit of AAE values. 

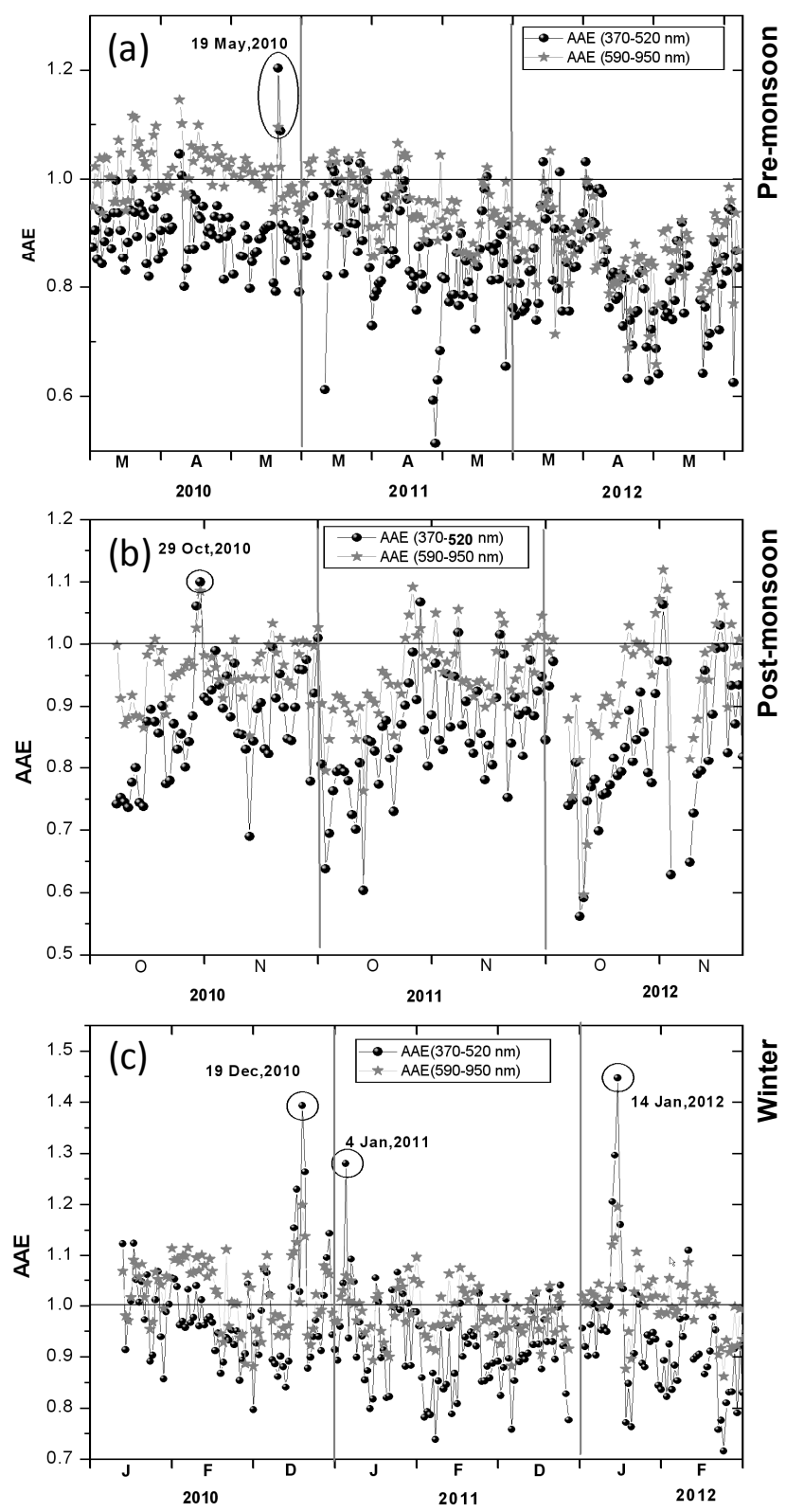

Figure 3. Daily average AAE during (a) pre-monsoon, (b) post-monsoon and (3) winter seasons of 2010, 2011 and 2012.

\section{Acknowledgement}

The authors gratefully acknowledge the support provided by the Director, NRSC; Deputy Director (ECSA) and Group Director, Atmospheric \& Climate Sciences Group (ACSG) for necessary help at various stages of this work and ISRO-GBP, ARFI for funding the project. The authors gratefully acknowledge the NOAA Air Resources Laboratory (ARL) for the provision of the HYSPLIT transport and dispersion model and/or READY website (http://www.arl.noaa.gov/ready.php) used in this publication. We acknowledge MODIS fire team for acquiring the MODIS active fire location.
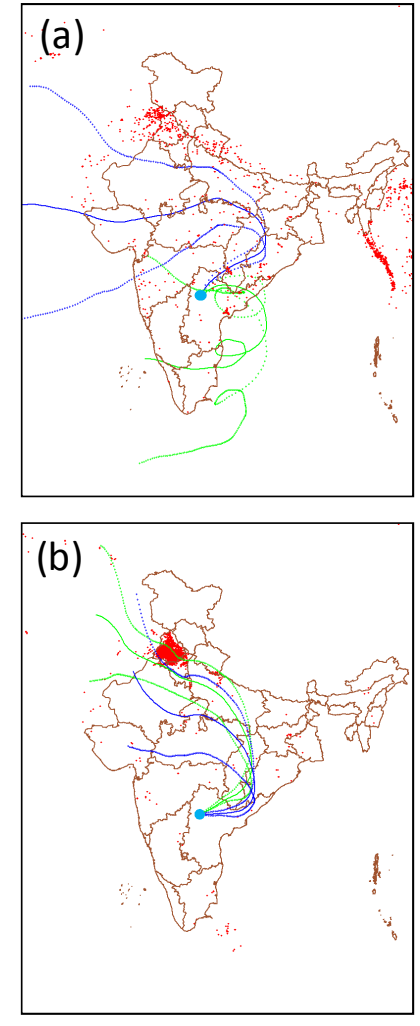

\section{Legend}

7 days backward trajectories ending at Hyderabad on

(a) 19 May, 2010

(b) 29 October, 2010

(c) 14 January, 2012

Superimposed with

MODIS derived fire

locations (7 days).

(c)

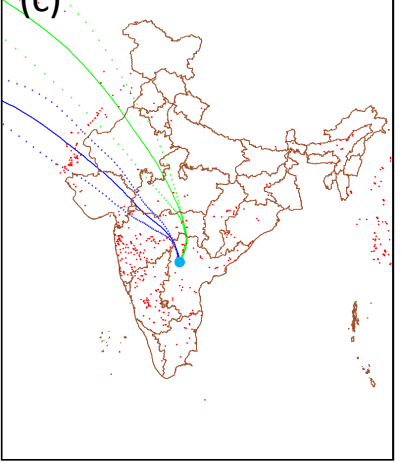

- Trajectory at $1 \mathrm{~km} \mathrm{AGL}$

\section{Trajectory spread} (0-23hrs UTC) at $1 \mathrm{~km} \mathrm{AGL}$

- Trajectory at $2 \mathrm{~km} \mathrm{AGL}$

--.- Trajectory spread (0-23hrs UTC) at $2 \mathrm{~km} \mathrm{AGL}$

- Hyderabad

- Fire locations

Figure 4. Terra/Aqua MODIS derived fire locations $\left(60^{\circ}-100^{\circ} \mathrm{E}\right.$ and $0^{\circ}-40^{\circ}$ N) along with backward trajectories ending at Hyderabad at 2 levels of the atmosphere, $1000 \mathrm{~m}$ (green) and 2000m (blue) on (a) 19 May,2010 (b) 29 October,2010 and (c) 14 January, 2012.

\section{References}

[1] T.C. Bond, D.G. Streets , K.F. Yarber, S.M. Nelson., J.H. Woo, Z. Klimont, "A technology-based global inventory of black and organic carbon emissions from combustion," J.Geophys. Res., 2004, 109, D14203, 2004.

[2] K.H. Kim, K. Sekiguchi, S. Kudo, and K. Sakamoto, " Characterisitics of Atmospheric Elemental Carbon (Char and Soot) in Ultrafine and Fine Particles in a Roadside Environmental, Japan," Aerosol Air Qual. Res. 11: 1-12, 2011.

[3] J. Hansen, Mki. Sato, R. Ruedy, A. Lacis, and V. Oinas, "Global warming in the twenty-first century: An alternative scenario," Proc. Natl. Acad. Sci., 97, 9875-9880, doi:10.1073/pnas.170278997, 2000. 
[4] S. A. Twomey, M. Piepgrass, and T.L. Wolfe, "An assessment of the impact of pollution on global cloud albedo," Tellus B. 36, 356-366, 1984.

[5] T.C. Bond, S.J. Doherty, D.W. Fahey, P.M. Forster, T. Berntsen, B.J. DeAngelo, M.G. Flanner, S. Ghan, B. Kärcher, D. Koch, S. Kinne, Y. Kondo, P. K. Quinn, M. C. Sarofim, M. G. Schultz, M. Schulz, C. Venkataraman, H. Zhang, S. Zhang, N. Bellouin, S. K. Guttikunda, P. K. Hopke, M. Z. Jacobson, J. W. Kaiser, Z. Klimont, U. Lohmann, J. P. Schwarz, D. Shindell, T. Storelvmo, S. G. Warren, C. S. Zender, " Bounding the role of black carbon in the climate system: A scientific assessment," J. Geophys. Res .DOI:10.1002/jgrd.50171, 2013.

[6] S. Menon, J.E. Hansen, L. Nazarenko, and Y. Luo, "Climate Effects of Black Carbon Aerosols in China and India," Science 297: 2250-2253, 2002.

[7] C. Wang, "A modeling study on the climate impacts of black carbon aerosols," J. Geophys. Res. 109, DO3 106. doi:10.1029/2003JD004084, 2004.

[8] V. Ramanathan, and G. Carmichael "Global and regional climate changes due to black carbon," Nature Geosci., 1, $221-227,2008$.

[9] M.Z. Jacobson, "Short-term effects of controlling fossil-fuel soot, biofuel soot and gases, and methane on climate, arctic ice, and air pollution health," J. Geophys. Res., 115, D14209, doi:10.1029/2009JD013795,2010.

[10] J.M. Lobert, and J. Warnatz, "Emission from the combustion process in vegetation," Fire in the Environment: The Ecological, Atmospheric, and Climatic Importance of Vegetation Fires, edited by P.J. Crutzen and J.G. Glodhammer, pp.15-37, John Wiley, New York, 1993.

[11] K.V.S. Badarinath, S.K. Kharol, A.R. Sharma, and V. Krishna Prasad, "Analysis of aerosol and carbon monoxide characteristics over Arabian Sea during crop residue burning period in the Indo-Gangetic Plains using multi-satellite remote sensing datasets," J. Atmos. Solar-Terr. Phys., 71, 1267-1276, 2009a.

[12] K.V.S. Badarinath, S.K. Kharol, and A.R. Sharma, "Long-rangetransport of aerosols from agriculture crop residue burning inIndo-Gangetic Plains - A study using LIDAR, ground measurements and satellite data," J. Atmos. Solar-Terr. Phys., 71, 112-120, 2009b.

[13] C. Venkataraman, G. Habib, A. Eiguren-Fernandez, A.H. Miguel, and S.K. Friedlander, "Residential biofuels in South Asia, Carbonaceous aerosol emissions and climate impacts," Science, 307, 1454-1456, 2005.

[14] D. Ganguly, A. Jayaraman, T.A. Rajesh, and H. Gadhavi, "Wintertime aerosol properties during foggy and nonfoggy days over urban center Delhi and their implications for shortwave radiative forcing," J. Geophys. Res., 111, D15217, doi: 10.1029/2005JD007029, 2006.

[15] K.M. Latha, and K.V.S. Badarinath, "Seasonal variations of black carbon aerosols and total aerosol mass concentrations over urban environment in India," Atmos. Environ., 39, 4129-4141, 2005.

[16] S.S. Babu, and K.K. Moorthy, "Aerosol black carbon over tropical coastal station in India," Geophys. Res. Lett., 29, 2098, doi:10.1029/2002GL015662. 2002.

[17] Bergstrom, R. W., Russell, P. B., \& Hignett, P. (2002).
Wavelength dependence of the absorption of black carbon particles: Predictions and results from the TARFOX experiment and implications for the aerosol single scattering albedo. Journal of the Atmospheric Sciences, 59(3).

[18] Kirchstetter, T. W., Novakov, T., \& Hobbs, P. V. (2004).Evidence that the spectral dependence of light absorption by aerosols is affected by organic carbon. Journal of Geophysical Research: Atmospheres (1984-2012), 109(D21).

[19] Bond, T. C., \& Bergstrom, R. W. (2006). Light absorption by carbonaceous particles: An investigative review. Aerosol Science and Technology, 40(1), 27-67.

[20] Smith, D. M., Keifer, J. R., Novicky, M., \& Chughtai, A. R. (1989). An FT-IR Study of the Effect of Simulated Solar Radiation and Various Particulates on the Oxidation of $\mathrm{SO}<$ sub $>2</$ sub $>$. Applied spectroscopy, 43(1), 103-107.

[21] Kirchner, U., Scheer, V., \& Vogt, R. (2000). FTIR spectroscopic investigation of the mechanism and kinetics of the heterogeneous reactions of $\mathrm{NO} 2$ and $\mathrm{HNO} 3$ with soot. The Journal of Physical Chemistry A, 104(39), 8908-8915.

[22] Fuller, K. A., Malm, W. C., \& Kreidenweis, S. M. (1999). Effects of mixing on extinction by carbonaceous particles. Journal of Geophysical Research: Atmospheres (1984-2012), 104(D13), 15941-15954.

[23] A.D. A. Hansen, H. Rosen, and T. Novakov, "The Aethalometer: An instrument for the real-time measurements of optical absorption by aerosol particles," Sci. Total Environ., 36, 191-196, 1984.

[24] Weingartner, E, H. Saathoff, M. Schnaiter, N. Streit, B. Bitnar, U. Baltensperger, Absorption of Light by Soot Particles: Determination of the Absorption Coefficient by Means of Aethalometer;" J. Aerosol Sci., 34, 1445-1463, 2003.

[25] K.K. Moorthy, S.S. Babu, S.K. Satheesh, "Temporal heterogeneity in aerosol characteristics and the resulting radiative impact at a trpical coastal station-Part 1: Microphysical and optical properties," Ann. Geophys., 25, 2293-2308, 2007.

[26] L. Giglio, J. Descloitres, C.O. Justice, Y.J. Kaufman, "An enhanced contextual fire detection algorithm for MODIS," Remote Sensing of Environment, 87 273-282, 2003.

[27] R.B. Stull, R. B. "An Introduction to Boundary Layer Meteorology,” Springer, New York, 1998.

[28] P. Yan," Study on the Aerosol Optical Properties in the Background Regions in the East Part of China (in Chinese with English Abstract),” Ph. D. Thesis, Peking University, 2006.

[29] X.L. Pan, X.L. "Observation Study of Atmospheric Aerosol Scattering Characteristics as a Function of Relative Humidity (in Chinese with English Abstract)," Ph. D. Thesis, Chin. Acad. of Meteorol. Sci., Bejing, 2007.

[30] R.W. Bergstrom, P. Pilewskie, P.B. Russell, J. Redemann, T.C. Bond, P.K. Quinn, and B. Sierau, "Spectral absorption properties of atmospheric aerosols," Atmos. Chem. Phys., 7, 5937-5943, doi:10.5194/acp-7-5937-2007, 2007.

[31] P. S. Praveen, T. Ahmed, A. Kar, I. H. Rehman, and V. Ramanathan, "Link between local scale BC emissions in the Indo-Gangetic Plains and large scale atmospheric solar absorption," Atmos. Chem. Phys., 12, 1173-1187, 2012. 